\title{
Optimal Design of Trigeneration and District Energy in the Presence of Energy Storage
}

\author{
S. Bruno ${ }^{1}$, S. Lamonaca ${ }^{1}$, M. La Scala ${ }^{1}$ and U. Stecchi ${ }^{1}$ \\ ${ }^{1}$ Dipartimento di Elettrotecnica ed Elettronica \\ Politecnico di Bari \\ via Re David 200, 70125, Bari, Italy \\ Phone/Fax number:+39 080 5963422(3658),e-mail: bruno@deemail.poliba.it, lascala@poliba.it
}

\begin{abstract}
The paper is aimed at exploring the opportunities given by the exploitation of different technologies for energy storage in the development of a trigeneration (trigen) and district energy project. In particular, the paper will be devoted to find the best cooling energy storage solution for the on-going San Paolo Power Park project in the City of Bari, Italy. The Power Park is a project that aims at producing energy and energy services through an optimal mix of renewables, CHP/DHC, hydrogen and other forms of energy. The energy produced in the central plant will be distributed in a suburban degraded area devoted to social housing, but also close to some significant energy users (airport, hospital and other major facilities). The optimization problem is solved by means of a two-step multiperiod algorithm. Test results are presented.
\end{abstract}

\section{Key words}

District heating and cooling, combined heat and power, thermal energy storage, chilled water storage, ice storage.

\section{Introduction.}

Combined Heat and Power (CHP), Combined Heat Cool and Power (CHCP) and District Heating and Cooling (DHC) are well known applications and represent the most effective (and efficient) solutions for the development of modern and sustainable urban settlements.

The technological and financial feasibility of investments in CHCP and DHC is not under discussion. Technologies for $\mathrm{CHCP}$ are in general mature and permit, thanks to their variety, efficient applications for any size or fuel. DHC systems are widely adopted and have been successfully implemented in different urban scenarios.

The high profitability of CHCP investments usually guarantee the possibility of having stable and fair tariffs for DHC customers. This is a very important feature, especially for those urban districts that are already populated and in which energy customers are already acquainted with their energy supplier and with the preexisting supply technology.
The profitability of a $\mathrm{CHCP} / \mathrm{DHC}$ investment can be increased (and as a consequence energy tariffs can be decreased) if the plant is suitably designed for allowing a maximum number of utilization hours in the year. A high number of utilization hours allows a fast recovery of the capital cost, especially in the first years following the investment (under the circumstance that money loses value with time at a certain discount rate). Moreover, it should be remembered that, under the Italian normative, the developer of a CHCP system is entitled at receiving white certificates for energy efficiency only for the first five years.

Clearly, a high utilization time is not enough. The maximum profitability for $\mathrm{CHCP}$ is reached when the plant operates at its nominal value and when cogenerated thermal energy is fully exploited. The full exploitation of this energy is a request not only for the maximization of the overall efficiency but also for reaching the minimum efficiency standards that, under present regulations, must be respected in order to receive white certificates.

Under these circumstances, and considering that electricity and thermal energy demands are in general not coordinated, CHCP plants are usually designed for producing, at nominal value, less than the average thermal base-load. In this way the plant can operate for the highest number of hours (during peaks and for baseload supply) and wasted thermal energy is minimized.

In CHCP/DHC systems energy storage units can be adopted for storing electricity or thermal energy exceeding actual load demand or produced during offpeak hours. Stored energy can be used during peak hours or, in general, when load demand exceeds produced energy. The presence of energy storage can therefore allow to reduce the size of the plant or capital costs, maximize CHCP efficiency and shorten investment payback time.

Please note that the management of energy storage is equivalent to load shifting procedures in demand-side management programs. Load shifting procedures are aimed at shifting power demand from peak to off-peak hours of the day. Analogously, load reduction corresponds to discharge of power from the storage, 
whereas a load increase is represented by storage charging [1].

The effect of Thermal Energy Storage (TES) systems is to decouple heat/cool generation from the provision of thermal energy during peak hours. This is particularly useful in DHC systems, since cooling loads tend to peak in those time of the day (and of the year) when high temperatures create maximum power demand [2].

Shifting loads from peak to off-peak hours permits to achieve economical results, reducing capital cost of investment and avoiding to purchase energy during those hours in which highest costs are usually experienced. Moreover, thanks to TES, it is possible to serve peak loads reliably using less heating/chilling capacity than the one required in conventional DHC system.

The paper will be devoted to find the best cooling energy storage solution for the on-going San Paolo Power Park project in the City of Bari, Italy. This optimal solution is calculated by means of a two-step multiperiod algorithm that permit to solve concurrently the problems of designing and operating the CHCP/TES system.

\section{The San Paolo Power Park project in the City of Bari, Italy.}

The Power Park is a project that aims at producing energy and energy services through an optimal mix of renewables, CHP/DHC, hydrogen and other forms of energy. Energy produced in the central plant will be distributed in a suburban degraded area devoted to social housing, but also close to some significant energy users (airport, hospital and other major facilities).

The choice of this location was based under multiple rationales. First of all, experimental projects for the integration of energy, environmental efficiency and urban mobility can be implemented more easily in areas, or districts, whose urbanization processes are not completed, or in which the urge for urban regeneration is particularly pushing. Moreover, practices reported in literature demonstrated how depressed areas could quickly industrially improve thanks to the reduction of energy tariffs [3].

An early best practice can be found in the Appleseed Project that, in the middle Eighties, contributed to the regeneration of a depressed urban area in New York, by applying a general $25 \%$ reduction in energy tariffs that led to the creation of 50,000 new jobs [3]. In general, urban regeneration, discounted innovative energy services and sustainable mobility can change working and living places, making the area attractive for new professional and business activities.

In the first phase of the project, the Power Park was supposed to supply electricity, heat and cooling only to four great customers. Then in further developments, taking advantage of the opinion expressed by the local authorities and of the above-quoted international practices, the project grew, aiming at providing discounted energy services for the greatest number of civilian customers in the Bari-San Paolo area.

The principal features of the proposed Power Park project are a trigen plant, a heat/cool distribution network, and a facility for hydrogen production and distribution. In [4] the authors proposed a scheme for coupling the CHP plant with a Steam Methane Reforming (SMR). In this scheme SMR is partially powered by the thermal flow provided by the exhausts of the gas turbine, leading to consistent fuel savings in the steam reforming process.

The approach presented in [4] is a CHCP/TES coupling solution of great interest because it permits to find an intersection point with the urban mobility system. This connection permits to integrate district energy in strategic planning and sustainable development of urban areas and, moreover, to take advantage of the fact that both thermal energy (natural gas) and public transportation services are supplied by municipalized companies that operate more or less at urban level and under the same financial/political management of municipal authorities. This study integrates the project developed previously in [4] since it is aimed to focus on the best CHCP/TES solution based on cool energy storage.

\section{Optimal design of the plant}

\section{A. Optimization of CHCP/TES design and operation}

The optimal design of a CHCP plant is in general a complex task. Problem solution is significantly affected, in both energetic and economical terms, by a great number of decision variables, and by fluctuating parameters such as energy prices or load profiles [5]. Further complexity is due to the fact that a CHCP plant design cannot be optimized without having performed an optimization of its operating conditions [6].

Many methods have proposed in literature for solving this problem, basing on heuristics, thermodynamics and non-linear programming [5, 7]. In general, problems can be formulated in the form of a mixed integer nonlinear problems (MINLP). The presence of TES introduces further complexity to the problem since dynamic constraints must be introduced for taking into account charging and discharging of storage units. In [8] the authors proposed a three-step optimization methodology for decomposing the original MINLP (mixed integer nonlinear programming) problem into NLP (nonlinear programming) subproblems and a dynamic programming problem.

The aim of this study is to find, given the set of future energy service customers, the optimal design of trigeneration and TES. The optimal solution can be considered as the one that maximises a specific financial performance index (for example Return Of Investment ROI or the Internal Rate of Return - IRR).

The optimization methodology adopted in this paper is mostly based on decoupling the optimization problem into two optimization problems, one related to the optimal design of main equipments (co-generator, chiller and TES) and the other to the optimization of operating conditions.

The solution of the first problem can be based on heuristic full-space research, given the limited extension of the variable sample space (the size of the equipment can vary in a limited range) and given the non-continuous nature of the variables that must be assessed (size of actual equipments). Moreover, the full-space research can 
rely on a database which gathers basic components technical requirements and costs.

In general this first optimization problem can be written as a

$$
\begin{gathered}
\max _{P_{E}, P_{T E S}, E_{T E S}} \operatorname{ROI}\left(P_{E}, P_{T E S}, E_{T E S}\right) \\
\mathrm{ROI}=\frac{\sum_{k=1}^{N} \frac{\left(R_{k}-C_{k}\right)}{(1+i)^{n_{k}}}}{C_{0}}
\end{gathered}
$$

where $P_{E}, P_{T E S}$ and $E_{T E S}$ are respectively the electric power rate of the cogenerator, the power of the chiller used for storage and the quantity of storable energy; $k$ is the generic time period, $N$ is the total number of time periods along the life of the plant, $n_{k}$ is the number of years that have passed from the initial investment during the time period $k, i$ is the discount rate, $C_{0}$ is the value of the initial investment.

$R_{k}$ and $C_{k}$ in eqn. (2) represent respectively the expected total revenues and costs during the time period $k$. Revenues and costs are evaluated according to management strategy and by solving a second optimization problem.

This problem is formulated on periodical basis, exploits aggregated data contained in thermal and cool load duration curves and takes into account the chosen management strategy of TES.

In general, TES can be managed by three strategies: full, near-full and partial storage [9]. In the specific project under development, partial storage is adopted to cogenerate electricity also during peaking hours of the day (and therefore when the maximum selling tariffs are available). At the same time, TES technology is adopted for following thermal demand when the production system operate constantly at nominal conditions [5]. The requirement of operating the co-generator close to its nominal capacity is also derived by the fact that efficiency of gas turbines decreases rapidly when moving the operation point away from the nominal value.

Figure 1 represents pictorially the management strategy adopted in this paper. The load duration curve is referred to a specific period of time $\left(h_{\max }\right)$ and therefore can be calculated on seasonal, monthly, weekly or daily basis. The proposed approach is aimed at finding the utilization time $\left(h_{u}\right)$ that maximized profits and the specific time period under analysis.

In our assumptions, the $\mathrm{CHCP}$ unit will be on as long as its maximum thermal capability $\left(P_{t_{\max }}\right)$ is less than thermal demand $\left(h<h^{*}\right)$. This choice is based on the rationale that thermal demand peaking hours for civilian customers are roughly concomitant with electric demand peaking hours (from morning to late afternoon) and that electric energy should be produced and sold when electricity prices are higher (i. e. during peaks).

When the maximum thermal capability $\left(P_{t \max }\right)$ is higher than demand $\left(h>h^{*}\right)$, the unit can still be operated at its nominal value. Thermal energy in excess will be partly used for charging the TES (according to a maximum charging power $\left.P_{C \text { tes }}\right)$ and partly lost. Area B in Fig. 1 represents the overall stored energy, whereas area $\mathrm{A}$ is the quantity of wasted thermal energy. Clearly B does not represent the required size of storage because usually charge/discharge cycle have a daily period, whereas the area $\mathrm{B}$ is referred to the time-period duration $h_{\max }$. It represents the actual storage on a daily basis only when the duration curve is referred to a single day.

During peaks, thermal demand will partially covered by stored energy that will be supplied with a maximum discharging power $P_{D \text { tes }}$. The area $\mathrm{C}$ represents the energy discharged in the time-period under study. Clearly charged energy $\mathrm{B}$ is always greater than discharged energy $\mathrm{C}$ (inequality constraint).

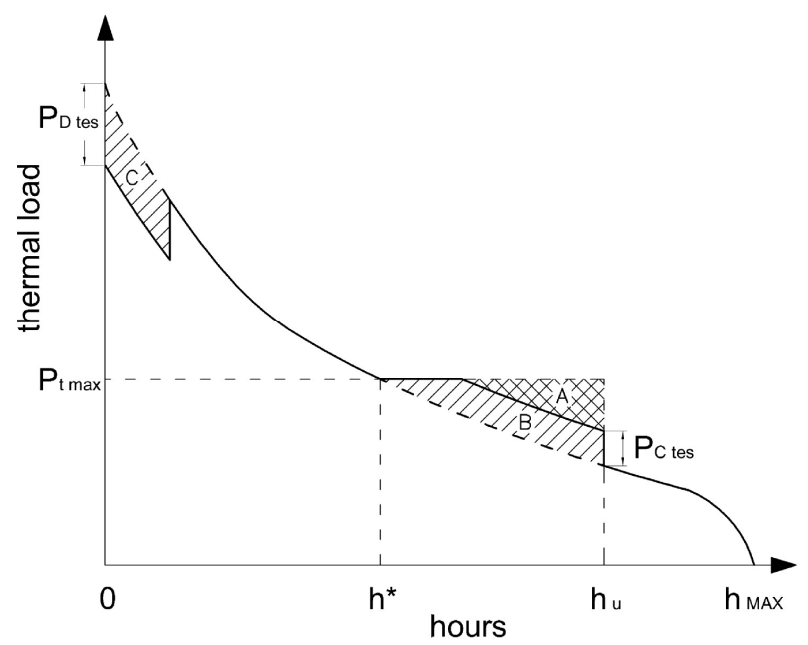

Fig. 1. CHCP/TES operating strategy during a specific timeperiod.

According to this management strategy revenues and costs can be evaluated by solving the following optimization problem:

$$
\max _{h_{u}^{k}}\left(R_{k}-C_{k}\right)
$$

subject to

$$
\begin{gathered}
E_{G H}^{k}=E_{D H}^{k} \\
E_{G C}^{k}=E_{D C}^{k} \\
E_{D I S}^{k} \leq \alpha \cdot E_{C H A}^{k}
\end{gathered}
$$

where $E_{D H}^{k}, E_{D C}^{k}, E_{G H}^{k}$ and $E_{G C}^{k}$ are demanded and generated heat and cool during the time period $k$. $E_{C H A}^{k}$ and $E_{D I S}^{k}$ represent respectively the energy charged during the time-period $k$ (represented as area $\mathrm{B}$ and $\mathrm{A}$ in Fig. 1), whereas $\alpha$ is a decreasing factor related to thermal losses.

Please note that by adopting shorter time-period it is possible to better assess an optimal operative strategy and to find the optimal dimension of the energy storage tank. Clearly, the solving algorithm will get slower if it must clear a greater number of shorter periods. Short timeperiods should be adopted only when demand chronological curves are estimated with sufficient confidence on their reference period.

\section{$B$. The proposed algorithm}

The adopted algorithm starts having set the technologies that will be adopted for the main equipments (for example gas turbine for cogeneration and chilled water tank for cool storage). The main variables are then given by the size of such equipments, whereas all other parameters can be derived those variables. 
The adopted algorithm sets the values of such variables and then operates a research of the optimal value of utilization time (for both co- and trigeneration) for each year in the operating life of the plant. Having supposed that the plant will be ready to cogenerate during 6 months of the year (from October to March) and to trigenerate in the other six months (from April to September) the algorithm searches, for both cogeneration and trigeneration, the utilization time that maximize net cashflows during the year. Such research is supposed to be run on annual basis in order to keep into account the annual increase of demand and also the fluctuation of energy prices.

Having found the optimal value of utilization hours, and having therefore assessed the future best management strategy for the plant, the algorithm can compute all financial performance indexes that are necessary for evaluating the profitability of the investment (NPV, ROI, DPBP, IRR, etc.).

The algorithm stores such values and goes back, fixing a new set of control variables, evaluating new financial performance indexes, and so on.

Given the nature of the problem (long-term planning) the computational time has not be considered as a main issue, but, in general, the algorithm can be speeded-up by implementing any other optimization technique such as gradient-based or meta-heuristic methods. Moreover, since the optimization analysis is performed following a chronological order, the solution found for a specific time-period can be used for the next one, speeding up the optimization.

\section{Load duration curves}

As already mentioned the San Paolo project is aimed at offering discounted energy service to a set of residential and civilian customers in a socially degraded area of the city. The project was developed considering that energy will be supplied to four major civilian facilities and to a set of residential customers. These four major facilities are police barracks, a police station, an airport and a hospital.

Load duration curves have been obtained adopting the daily thermal load profiles already present in the literature [5, 10-13]. Load profiles of the four civilian facilities have been suitably adapted in order to replicate aggregated load demand historical data. The fifth user represents residential customers (about 5,000 apartments).

Monthly heating and cooling thermal demand for all users have been reported respectively in Table I and Table II. Figures 3 and 4 show cumulative aggregated yearly load duration curves for both heat and cool demand.

\section{Main hypotheses}

As already mentioned, under current assumption, the electricity produced in the Power Park is meant to be sold in the energy market. In calculations, the entire electricity production, having deducted a $3 \%$ necessary for self-consumption, is considered as injected in the power system and sold at the average price $80 € / \mathrm{MWh}$.
Table I. - Thermal heat monthly demand

\begin{tabular}{|l|r|r|r|r|r|}
\hline Month & User 1 & User 2 & User 3 & User 4 & \multicolumn{1}{|c|}{ User 5 } \\
\hline Gen. & 909 & 812 & 579 & 1248 & 6412 \\
\hline Feb. & 808 & 581 & 414 & 874 & 4583 \\
\hline Mar. & 632 & 422 & 301 & 865 & 3334 \\
\hline Apr. & 455 & 176 & 126 & 492 & 1390 \\
\hline May. & 354 & 51 & 37 & 366 & 404 \\
\hline Jun. & 202 & 42 & 30 & 293 & 334 \\
\hline Jul. & 177 & 26 & 18 & 158 & 203 \\
\hline Aug. & 177 & 14 & 10 & 206 & 113 \\
\hline Sep. & 303 & 36 & 26 & 269 & 283 \\
\hline Oct. & 404 & 118 & 84 & 400 & 935 \\
\hline Nov. & 606 & 488 & 348 & 722 & 3855 \\
\hline Dec. & 758 & 913 & 651 & 706 & 7208 \\
\hline TOT & $\mathbf{5 7 8 5}$ & $\mathbf{3 6 8 1}$ & $\mathbf{2 6 2 6}$ & $\mathbf{6 5 9 9}$ & $\mathbf{2 9 0 5 3}$ \\
\hline
\end{tabular}

Table II. - Cooling monthly demand

\begin{tabular}{|l|r|r|r|r|r|}
\hline Month & \multicolumn{1}{|c|}{ User 1 } & \multicolumn{1}{|c|}{ User 2 } & \multicolumn{1}{l|}{ User 3 } & \multicolumn{1}{l|}{ User 4 } & \multicolumn{1}{l|}{ User 5 } \\
\hline Gen. & 202 & 0 & 0 & 0 & 0 \\
\hline Feb. & 227 & 0 & 0 & 0 & 0 \\
\hline Mar. & 303 & 0 & 0 & 0 & 0 \\
\hline Apr. & 227 & 0 & 0 & 0 & 0 \\
\hline May. & 328 & 0 & 0 & 0 & 0 \\
\hline Jun. & 606 & 241 & 172 & 432 & 1401 \\
\hline Jul. & 611 & 703 & 502 & 1261 & 4089 \\
\hline Aug. & 596 & 523 & 373 & 938 & 3041 \\
\hline Sep. & 404 & 207 & 147 & 370 & 1201 \\
\hline Oct. & 263 & 0 & 0 & 0 & 0 \\
\hline Nov. & 177 & 0 & 0 & 0 & 0 \\
\hline Dec. & 152 & 0 & 0 & 0 & 0 \\
\hline TOT & $\mathbf{4 0 9 7}$ & $\mathbf{1 6 7 4}$ & $\mathbf{1 1 9 4}$ & $\mathbf{3 0 0 1}$ & $\mathbf{9 7 3 2}$ \\
\hline
\end{tabular}

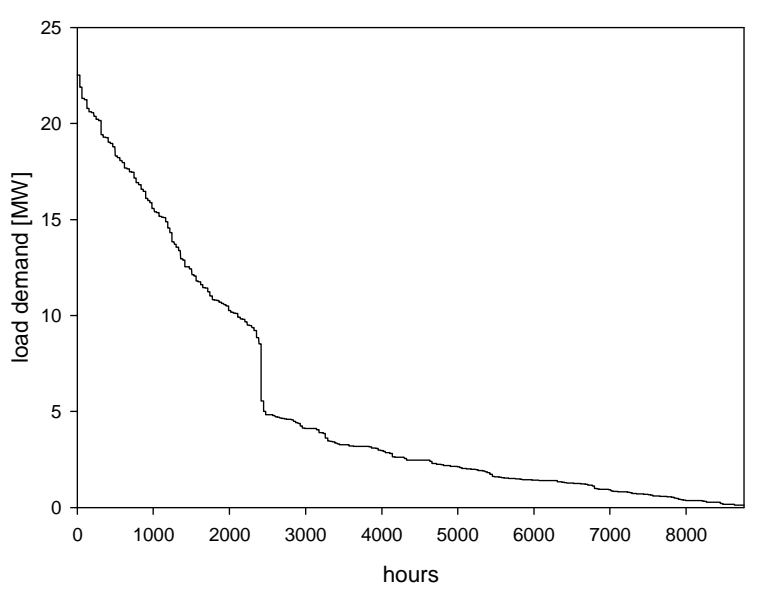

Fig. 2. Cumulative heating load duration curve

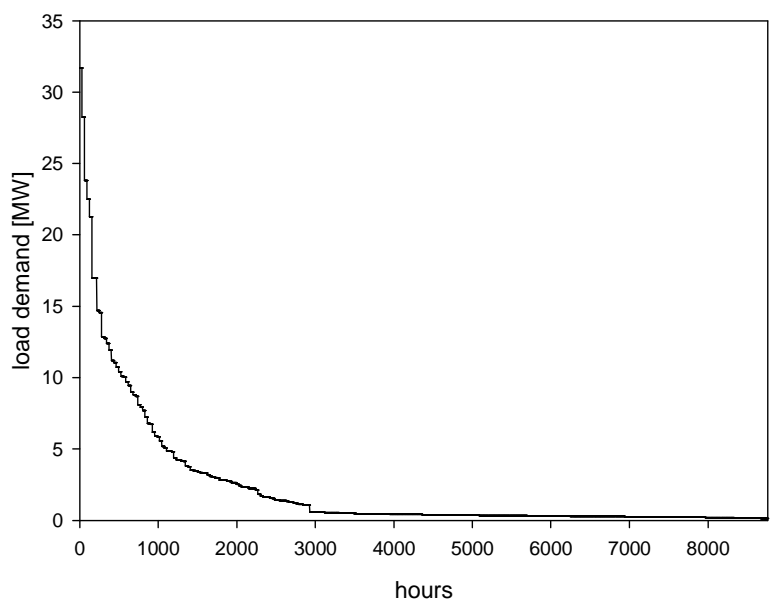

Fig. 3. Cumulative cooling load duration curve 
The co-generated thermal energy is used for districting heating. In this case thermal losses due to the distribution in the heating network, having a $10 \mathrm{~km}$ extension, can be estimated in around 7\%. Cooling and heating services will be sold at discounted tariffs $(65 € / \mathrm{MWh}$ for heating and $56 € / \mathrm{MWh}$ for cooling energy). These prices have been obtained by applying a $25 \%$ discount on current heat and cool tariffs, coherently with urban regeneration objectives shared with the above quoted Appleseed Project [3].

Production costs were evaluated considering a cost of natural gas of $0.32 € / \mathrm{m}^{3}$. The operation and maintenance costs (O\&M) are assumed in the proportion of $4 \%$ of the investment for the gas turbine and of $2 \%$ for the district heating network. The dependence of gas turbine efficiency with respect to its size has been modelled according to [14].

Further revenues are expected by selling energy efficiency certificates, that according to the European regulation have a duration of 5 years starting from the first year of production. These certificates, evaluated on the basis of the expected production and current market values, are expected to bring further revenues for 135,000 $€$ per year.

Total investment costs have been calculated considering two components. A fix component takes into account all those costs that have a null or negligible dependence to the size of the cogeneration plant (such as the district heating network, heating distribution equipments, interconnection line, soundproofing cabin, ancillary works). The second investment cost component is given by those equipments whose cost is strongly dependant on the size. Such component takes into account costs for gas turbine, chiller, recovery boiler, auxiliary boiler, TES device and storage. In the proposed solver, the evaluation of such costs is subsequent to the management optimization because that is necessary in order to estimate the minimum size of certain equipments such as the auxiliary boiler or the energy storage tank.

\section{E. Cool energy storage}

According to [2] there are two families of TES technology: sensible heat storage (Chilled Water or $\mathrm{CHW}$ ) and latent heat storage (Ice TES).

In large scale applications, $\mathrm{CHW}$ technology can guarantee significant cost savings and capital cost even lower than conventional (non-TES) chiller plant. The principal drawback of this technology is that it requires a relatively large store tank volume.

Ice thermal storage is based on accumulation of cool energy in the form of ice at its freezing point $\left(0^{\circ} \mathrm{C}\right)$. Thus, the refrigeration equipment must operate at lower temperatures than the normal operating range for air conditioning applications. Ice TES exploits the latent heat necessary for the phase change in water-ice passage and, therefore, requires moderately compact storage volumes. Usually ice storage has initial costs $15-20 \%$ higher than chilled water storage. However, requiring 4-6 times less volume than $\mathrm{CHW}$, Ice TES can be the optimal solution when space is limited or installation costs are higher.

Ice TES can take advantage of different technologies for ice storage: ice-on-coil, sheet ice harvester, encapsulated ice, ice slurry [15]. In this study only those technologies that have a discharge fluid compatible with the conventional chilled water distribution system, will be taken into consideration (namely ice harvester and external melt ice-on coil).

Table III gathers all parameters and unitary costs that will be employed in test results. Data are mostly based on what reported in [15-16].

Table III. - Cost of cool thermal energy storing

\begin{tabular}{|l|r|r|}
\hline \multicolumn{1}{|c|}{ TES Technology } & $\begin{array}{c}\text { Chiller cost } \\
{[€ / \mathrm{kW}]}\end{array}$ & $\begin{array}{c}\text { Storage cost } \\
{[€ / \mathrm{kWh}]}\end{array}$ \\
\hline Chilled Water - CHW & $40-60$ & $9-21$ \\
\hline Ice Harvester & $200-300$ & $4-6$ \\
\hline External melt ice-on coil & $40-100$ & $10-14$ \\
\hline
\end{tabular}

\section{Test Results}

Test results have been carried out considering four test cases. Case A is referred to a plant design without cool storage. The other three cases, namely $\mathrm{B}, \mathrm{C}$ and $\mathrm{D}$, are referred to the employment of $\mathrm{CHW}$, external melt ice-on coil and ice harvest, respectively. For each case the best TES design has been evaluated by fixing the electric power capacity of the gas turbine $\left(P_{E}\right)$.

For each case a full-space research on control variables has been performed. Table IV shows how, in the case of no TES implemented, the best financial performance, in terms of ROI, can be achieved with a $7 \mathrm{MW}$ cogenerator. In this case a $35 \mathrm{MW}$ absorption chiller is needed for satisfy cool energy summer peaks. The overall initial cost is about $12,400,000 €$.

Table IV - Case A without cool TES

\begin{tabular}{|c|c|c|c|}
\hline$P_{E}[\mathrm{MW}]$ & NPV [€] & ROI & IRR \\
\hline 1 & $5,354,200$ & 0.535 & 0.147 \\
\hline 2 & $7,084,300$ & 0.681 & 0.164 \\
\hline 3 & $7,968,100$ & 0.738 & 0.171 \\
\hline 4 & $8,451,800$ & 0.754 & 0.173 \\
\hline 5 & $8,966,000$ & 0.773 & 0.175 \\
\hline 6 & $9,497,600$ & 0.791 & 0.178 \\
\hline 7 & $9,959,200$ & 0.803 & 0.179 \\
\hline 8 & $10,220,300$ & 0.798 & 0.179 \\
\hline 9 & $10,308,200$ & 0.781 & 0.177 \\
\hline 10 & $10,282,100$ & 0.756 & 0.174 \\
\hline
\end{tabular}

Table $\mathrm{V}$ shows how through the installation of a $\mathrm{CHW}$ storage system better financial performance indexes can be achieved. In this case, the best investment is given by a 4 MW gas turbine coupled with a 17 MW absorption chiller and a $47 \mathrm{MWh}$ storage tank, for a total capital cost of about $11,050,000$. In this case the presence of TES allows to reduce the size of the plant and significantly reduce capital costs.

Table V. - Case B with CHW TES

\begin{tabular}{|c|r|r|r|c|c|}
\hline $\begin{array}{c}P_{E} \\
{[\mathrm{MW}]}\end{array}$ & $\begin{array}{c}P_{T E S} \\
{[\mathrm{MW}]}\end{array}$ & $\begin{array}{c}E_{T E S} \\
{[\mathrm{MWh}]}\end{array}$ & $\begin{array}{c}\text { NPV } \\
{[€]}\end{array}$ & ROI & IRR \\
\hline 1 & 18.5 & 43.8 & $6,024,900$ & 0.610 & 0.155 \\
\hline 2 & 17.0 & 64.1 & $8,562,500$ & 0.814 & 0.179 \\
\hline 3 & 17.0 & 58.8 & $9,723,300$ & 0.897 & 0.189 \\
\hline 4 & 17.0 & 47.4 & $10,240,700$ & 0.926 & 0.192 \\
\hline 5 & 17.0 & 47.4 & $10,448,900$ & 0.911 & 0.191 \\
\hline 6 & 17.0 & 47.4 & $10,693,800$ & 0.901 & 0.190 \\
\hline 7 & 17.0 & 47.4 & $10,956,400$ & 0.893 & 0.190 \\
\hline 8 & 17.0 & 47.4 & $11,067,500$ & 0.874 & 0.188 \\
\hline 9 & 17.0 & 47.4 & $11,026,600$ & 0.844 & 0.184 \\
\hline 10 & 18.0 & 45.0 & $10,855,200$ & 0.806 & 0.180 \\
\hline
\end{tabular}


It is possible to make a comparison between case A and $\mathrm{B}$ considering test results for the same gas turbine capacity. If a $7 \mathrm{MW}$ turbine were chosen, capital costs in the presence of CHW TES are about 12,250,000 €. Even if this configuration needs more equipments (the TES unit) capital cost is lower than case A because a smaller absorption chiller can be installed.

This same reduction of capital costs cannot be achieved for other TES technologies (Tables VI and VII). In such cases, cool must be produced with an auxiliary chiller, devoted only to the production of stored cool, that has higher unitary costs (see Table III). For cases C and D, capital cost is always higher than case $\mathrm{A}$, and given the limited benefits brought by TES, investments are almost always less convenient.

In general, from Table VI and VII, external melt ice-on coil and ice harvesting technologies seem to be profitable only when employed for smaller size applications.

Table VI. - Case C with External Melt Ice TES

\begin{tabular}{|c|r|r|r|r|c|}
\hline $\begin{array}{c}P_{E} \\
{[\mathrm{MW}]}\end{array}$ & $\begin{array}{c}P_{T E S} \\
{[\mathrm{MW}]}\end{array}$ & $\begin{array}{c}E_{T E S} \\
{[\mathrm{MWh}]}\end{array}$ & $\begin{array}{c}\text { NPV } \\
{[€]}\end{array}$ & ROI & IRR \\
\hline 1 & 1.6 & 12.8 & $5,691,900$ & 0.559 & 0.149 \\
\hline 2 & 3.4 & 27.2 & $7,646,300$ & 0.709 & 0.167 \\
\hline 3 & 5.2 & 35.9 & $8,682,700$ & 0.767 & 0.174 \\
\hline 4 & 7.2 & 33.4 & $9,167,700$ & 0.782 & 0.176 \\
\hline 5 & 8.0 & 27.1 & $9,515,200$ & 0.789 & 0.177 \\
\hline 6 & 6.0 & 18.0 & $9,778,400$ & 0.794 & 0.178 \\
\hline 7 & 0 & 0 & $9,959,200$ & 0.803 & 0.179 \\
\hline 8 & 0 & 0 & $10,220,300$ & 0.798 & 0.179 \\
\hline 9 & 0 & 0 & $10,308,200$ & 0.781 & 0.177 \\
\hline 10 & 0 & 0 & $10,282,100$ & 0.756 & 0.174 \\
\hline
\end{tabular}

Table VII. - Case D with Ice Harvesting TES

\begin{tabular}{|c|r|r|r|c|c|}
\hline $\begin{array}{c}P_{E} \\
{[\mathrm{MW}]}\end{array}$ & $\begin{array}{c}P_{\text {TES }} \\
{[\mathrm{MW}]}\end{array}$ & $\begin{array}{c}E_{\text {TES }} \\
{[\mathrm{MWh}]}\end{array}$ & $\begin{array}{c}\text { NPV } \\
{[€]}\end{array}$ & ROI & IRR \\
\hline 1 & 1.6 & 12.8 & $5,560,700$ & 0.539 & 0.147 \\
\hline 2 & 1.2 & 9.5 & $7,249,900$ & 0.682 & 0.164 \\
\hline 3 & 0.4 & 3.1 & $8,026,900$ & 0.738 & 0.171 \\
\hline 4 & 0 & 0 & $8,451,800$ & 0.754 & 0.173 \\
\hline 5 & 0 & 0 & $8,966,000$ & 0.773 & 0.175 \\
\hline 6 & 0 & 0 & $9,497,600$ & 0.791 & 0.178 \\
\hline 7 & 0 & 0 & $9,959,200$ & 0.803 & 0.179 \\
\hline 8 & 0 & 0 & $10,220,300$ & 0.798 & 0.179 \\
\hline 9 & 0 & 0 & $10,308,200$ & 0.781 & 0.177 \\
\hline 10 & 0 & 0 & $10,282,100$ & 0.756 & 0.174 \\
\hline
\end{tabular}

\section{Conclusions}

The authors have explored the possible achievements, in terms of financial performances, that can be obtained by adopting cool Thermal Energy Storage (TES) technologies in the development of a Combined Heat Cool and Power (CHCP) and District Heating and Cooling (DHC) project.

In order to find the most efficient TES solution and ideal gas turbine size, an optimization problem has been formulated and solved by means of a two-step multiperiod algorithm. Such algorithm is able to solve concurrently the two decupled problems of optimal design of equipments (co-generator, chiller and TES) and optimization of operating conditions.

Test results were obtained for the case of large CHCP/DHC project in the South of Italy. Test results showed how through Chilled Water (CHW) TES it is possible to reduce capital costs and achieve better financial performances. Other technologies are not fit for this specific project and should be applied for smaller or different applications.

\section{References}

[1] D. Henning, "Cost Minimization for a Local Utility Through CHP, Heat Storage and Load Management", International Journal Of Energy Research, Vol. 22, pages 691-713, 1998.

[2] J. S. Andrepont, "Reducing Energy Costs and Minimizing Capital Requirements: Case Studies of Thermal Energy Storage (TES)", Proc. of $29^{\text {th }}$ Industrial Energy Technology Conference, New Orleans, LA, May 8-11, 2007.

[3] J. R. Manak, "Project Appleseed: electric rate incentives", IEEE Transaction on Power Systems, Vol. 3, No. 4, pp. 1833-1839, Nov. 1988.A. Author1, Book Title, Publisher, City (1996), pp. 154-162.

[4] S. Bruno, S. Lamonaca, M. La Scala, G. Rotondo, U. Stecchi, "Improving Energy Efficiency in a Power Park by the Integration of a Hydrogen Steam Reformer", Asia Pacific Power and Energy Engineering Conference (APPEEC 2009), March $28^{\text {th }}-30^{\text {th }} 2009$, Wuhan, China.

[5] M. A. Lozano, J. C. Ramos, L. M. Serra, "Cost optimization of the design of CHCP (combined heat, cooling and power) systems under legal constraints", Energy, 2009, doi:10.1016/j.energy.2009.08.022.

[6] E. Cardona, A. Piacentino "Optimal design of CHCP plants in the civil sector by thermoeconomics", Applied Energy, Vol. 84, No. 7-8, pages 729-748, Jul-Aug 2007.

[7] G. Chicco and P. Mancarella, "Distributed multigeneration: A comprehensive view", Renewable and Sustainable Energy Reviews, Vol. 13, No. 3, pages 535551, April 2009.

[8] J. H. Kim and C. Han, "Short-Term Multiperiod Optimal Planning of Utility Systems Using Heuristics and Dynamic Programming”, Ind. Eng. Chem. Res., Vol. 40, No. 8, pages 1928-1938, 2001.

[9] I. Dincer and M. A. Rosen, "Energetic, environmental and economic aspects of thermal energy storage systems for cooling capacity", Applied Thermal Engineering, Vol. 21, No. 11, pages 1105-1117, August 2001.

[10] R. Loschi, "Valutazioni tecnico-economiche sulla gestione del servizio energie e della cogenerazione in un complesso ospedaliero", Atti del Convegno AEIT - La cogenerazione diffusa ̀̀ un'opzione valida per la produzione dei flussi energetici necessari?, Milano, October $27^{\text {th }}, 2003$.

[11] E. Cardona, A. Piacentino, F. Cardona, "Energy saving in airports by trigeneration. Part I: Assessing economic and technical potential", Applied Thermal Engineering, Vol. 26, pages 1427-1436, 2006.

[12] T. T. Chow, K. F. Fong et al., "Energy modelling of district cooling system for new urban development", Energy and Buildings, Vol. 36, pages 1153-1162, 2004.

[13] T. T. Chow, W. H. Au et al. "Applying district-cooling technology in Hong Kong", Applied Energy, Vol. 79, pages 275-289, 2004.

[14] Ricerca di Sistema (2002), Report n. GENDIS/SFR/02/03 on "Analisi tecnico-economica di sistemi idonei ad applicazioni cogenerative nel settore terziario", available at http://www.ricercadisistema.it

[15] IEA (2002), report on IEA District Heating and Cooling: Optimization of Cool Thermal Storage and Distribution, available at http://www.svenskfjarrvarme.se.

[16] K. Roth, R. Zogg, J. Brodrick, "Cool Thermal Energy Storage”, ASHRAE Journal, Vol. 48, pages 94-96, September 2006. 